ISSN electrónico: 2172-9077

https://doi.org/10.14201/fjc2018161130

\title{
LA LINTERNA MÁGICA COMO SOPORTE PUBLICITARIO. RECORRIDO HISTÓRICO POR NOTICIAS, ANÉCDOTAS Y PATENTES
}

\section{The Magic Lantern as a Means of Advertising. Historical Tour by News, Anectotes and Patents}

\author{
Dra. María Begoña SÁNCHEZ GALÁN \\ Profesora Ayudante Doctor. Universidad de Valladolid, España \\ E-Mail: mariabegona.sanchez@uva.es \\ https://orcid.org/0000-0002-3578-8446
}

Fecha de recepción del artículo: 02/10/2017

Fecha de aceptación definitiva: 24/03/2017

\begin{abstract}
RESUMEN
La linterna mágica, artilugio en el que encontramos el origen de la actual cultura del audiovisual, fue también la cuna en la que nació y se desarrolló una parte de la publicidad moderna. En el último tercio del siglo XIX, en un intento por salvar la creciente saturación publicitaria que ya se observaba en la prensa diaria y en las paredes de las calles de las grandes ciudades, los anunciantes, los proyeccionistas y un nutrido grupo de inventores, comenzaron a recurrir a la linterna mágica como medio para exhibir los anuncios. Buscaban con ello dotar de espectacularidad a la publicidad y atraer la atención de unos consumidores que estaban viviendo en primera persona el paso de una sociedad agrícola e industrial a una economía basada en el consumo. Este artículo repasa de manera cronológica las fuentes de información que hablan de este proceso. A través de artículos de prensa, memorias de patentes y referencias bibliográficas, se establece una línea temporal que permite observar la evolución de las proyecciones publicitarias de linterna mágica y el deseo expreso de sus promotores de vincular sus mensajes al mundo del ocio y del espectáculo, características que permanecen vigentes en la publicidad del siglo XXI.
\end{abstract}

Palabras clave: linterna mágica; publicidad audiovisual; diapositivas publicitarias; anuncios; patentes de invención publicitaria; historia de la publicidad.

\begin{abstract}
The magic lantern, the device in which we can find the origins of the current audio-visual culture, was also the cradle of media advertising. During the last decades of the $19^{\text {th }}$ Century, in an attempt to face the growing advertising saturation that was already visible in the dairy press and on the walls of big cities, the advertisers, projectionists and a large group of inventors, began to turn to the magic lantern as a means for exhibiting all kind of advertisements. In doing so, they wanted to add a spectacular element to advertising which would ultimately succeed in attracting the attention of consumers, that were immersed in the transit from an agricultural and industrial society to an economy based on consumption. This article chronologically reviews the different sources in which it is possible to find information about the subject. Through newspapers articles, patents' records and bibliographic references, a timeline is laid down to observe the evolution of the use of magic lanterns for advertising purposes and their promoters' stated intention to link that messages to the leisure and entertainment realms, characteristics that are still evident in current $21^{\text {th }}$ Century advertising.
\end{abstract}

Key words: magic lantern; media advertising; advertising slides; advertisements; advertising patent; advertising history. 


\section{INTRODUCCIÓN. OBJETO Y METODOLOGÍA DE ESTA INVESTIGACIÓN}

La publicidad, entendida como un medio de comunicación al servicio del capitalismo de producción y consumo, comenzó a sistematizarse al amparo de las revoluciones industriales y al mismo tiempo que se desarrollaban las máquinas de vapor, las fábricas, los transportes, los nuevos modelos arquitectónicos, los espectáculos de proyección de imágenes, la fotografía, el ocio, la electricidad y el cine. Su historia está ligada a la historia de las sociedades modernas y, en ellas, la publicidad encontró toda una batería de soportes privilegiados para exponer, ante un público cada vez más numeroso, el discurso del consumo. A las páginas de periódicos y revistas, y a las fachadas y paredes de los edificios (lugares habituales en los que contemplar anuncios y carteles publicitarios), se unieron a finales del siglo XIX las estaciones de trenes, los escaparates, las sesiones de la linterna mágica y posteriormente el cine. Estados Unidos, país en el que el capitalismo de consumo se desarrolló con mayor celeridad, mostró al mundo entero las posibilidades que la publicidad le ofrecía al comercio. Le imitaron en este camino Gran Bretaña, Francia, Alemania y, en menor medida y a distintas velocidades, el resto de los países de Europa.

En el último tercio del siglo XIX los profesionales tenían clara la importancia de la publicidad en el desarrollo del comercio y en el éxito de la industria. Pongamos un ejemplo. Estamos en la España de 1876 y, en un artículo titulado 'Crónicas de Filadelfia', José Jordana y Morera nos cuenta el éxito que tienen los americanos en los negocios y su tendencia a hacer publicidad por medio de cualquier soporte, incluidas las proyecciones de linterna mágica:

La publicidad como medio de difusión y propagación de los productos del trabajo es aquí uno de los elementos más necesarios para hacer fortuna [...]. Los periódicos suelen ser el vehículo ordinario de la publicidad, pero hay además mil medios y formas por las cuales se llega al mismo término $[\ldots]$.

Los grandes carteles o rótulos iluminados por el gas o luz eléctrica durante la noche, ya no encuentran espectadores de puro gastados. En clase de efectos ópticos, uno de los más nuevos que he visto es el que ante una turba de curiosos aparece todas las noches, desde hace unos días, en la calle de Chesnut, y que consiste en un gran telón donde, por medio de una linterna mágica, hace aparecer el industrial que explota este ramo de nocturna publicidad sendos anuncios de fabricantes e industriales, alternando con figurones de formas raras y extravagantes, con los cuales detiene a los paseantes cautivando su atención por la novedad del procedimiento. (Crónicas, 1876, pp. 214-215).

Sacar a la luz esta y otras referencias, y con ello averiguar el papel que jugaron las linternas mágicas en la configuración del discurso publicitario de la modernidad, es el principal objetivo de esta investigación. En el recorrido por los distintos soportes publicitarios que se comenzaron a utilizar en el siglo XIX la linterna mágica jugó un papel importantísimo, en tanto en cuanto fue el primer soporte que puso en contacto la publicidad con la pantalla. Este hecho es de sobra conocido entre los expertos, aunque bien es cierto que la bibliografía que nos habla de este fenómeno es escasa y, en ocasiones, difícil de localizar. Esto hace que sea muy difícil calcular el alcance de un recurso que, para nosotros, marca el inicio de la actual publicidad audiovisual. En este artículo nos proponemos recuperar las fuentes más importantes de las que disponemos y construir con ellas la historia del encuentro de la publicidad con las linternas mágicas. Nos interesa, además, prestar especial atención a la presencia de 
este soporte en España, donde parece que la utilización de la linterna como medio publicitario no despertó el mismo interés que en el resto del mundo.

Para construir nuestro relato hemos seguido un esquema clásico de investigación histórica y hemos realizado una amplia búsqueda de referencias en fuentes bibliográficas, hemerográficas y en archivos. Como resultado hemos obtenido una interesante muestra de datos deslavazados, ubicados en distintos momentos y lugares, que hemos integrado en una sola narración. La idea es construir una panorámica que nos permita observar el fenómeno en su conjunto, dejar de considerar que las piezas de este puzle son manifestaciones aisladas y colocarlas todas juntas, encajar unos fragmentos con otros, para ver qué imagen nos devuelven. Para ello, hemos elegido ordenar las teselas de este mosaico en orden cronológico. En un primer momento barajamos otras opciones, como una distribución geográfica o temática, pero desde estos puntos de vista se perdía la posibilidad de observar el fenómeno de manera simultánea dentro del contexto de la historia europea. De ahí que este artículo incorpore cada referencia en base a una estructura temporal.

Este hilo cronológico arranca en el último tercio del siglo XIX y finaliza en la segunda década del siglo XX. Este marco temporal es muy importante porque, cuando se estudia la relación de las linternas mágicas con la publicidad, se tiende a incluir los ejemplos de cristales y proyectores fabricados para los espectáculos cinematográficos. Estos cristales, a los que habitualmente llamamos 'diapositivas publicitarias', y que se mantuvieron vivos hasta la segunda mitad del siglo XX, fueron herederos directos de las linternas mágicas, pero conceptualmente forman parte de un espacio diferente. Los espectáculos de linterna mágica y el cine reúnen características propias y bien diferenciadas que los convierten en dos soportes publicitarios distintos. De ahí que nuestro análisis se limite exclusivamente al entorno específico de la linterna mágica.

Para establecer un marco temporal adecuado nos hemos apoyado en la periodización propuesta por Francisco Javier Frutos y Carmen López (2010), que ubican el comienzo de la comercialización en serie de la linterna mágica en el último cuarto del siglo XIX y fijan el inicio de su decadencia en las primeras décadas del siglo XX. Esta época coincide con los años en los que se forjó la sociedad de consumo en los países desarrollados y es, a su vez, el período en el que la publicidad puso en práctica nuevas estrategias comerciales y científicas para impulsar el consumo (Ewen, 1976).

Nuestro relato se centra, a su vez, en las fuentes que hablan de la publicidad como herramienta comercial. En la actualidad, cuando hablamos de 'publicidad', vinculamos automáticamente el término al consumo. No era así en el período que estamos estudiando y por eso hay que tener mucho cuidado al analizar las referencias que aparecen cuando realizamos búsquedas bajo el término 'publicidad'. A finales del siglo XIX era habitual 'dar a la publicidad' las noticias, las leyes, las resoluciones judiciales o los avisos, sin que ninguno de estos hechos tuviera relación alguna con el comercio. Las distintas acepciones de la palabra 'publicidad' nos devuelven documentos que es necesario filtrar para no cometer errores, especialmente cuando los textos hacen alusión a la 'publicidad' destinada a fomentar la educación y a la exposición de ideologías políticas, lo que habitualmente denominamos 'propaganda'. Nuestro relato no se detiene en estas temáticas y se centra en el uso de la linterna mágica como medio para anunciar artículos de consumo.

El texto está construido a partir de los datos más importantes que hemos conseguido localizar, pero queremos pensar que hay muchos más. Confiamos en que irán apareciendo nuevas informaciones a medida que se digitalicen y difundan los materiales que esperan su turno en los archivos de instituciones y publicaciones periódicas. Este es solo el inicio de una historia que aún puede desvelar muchos secretos. 


\section{Primeros contactos de la linterna mágica CON LA PUblicidad: 1868-1889}

La publicidad moderna se forjó durante el período que comprende el último tercio del siglo XIX y el primero del siglo XX y tiene su origen en la cultura de masas y en los efectos que esta tuvo sobre el consumo. En este período el capitalismo, hasta ese momento centrado en la producción, evolucionó hacia esquemas más elaborados en los que el consumo masivo de productos se convirtió en la respuesta a los incipientes problemas de superproducción a los que se enfrentaban las fábricas. Los anuncios demostraron ser la mejor herramienta para favorecer el cambio y en esta etapa se dieron a conocer los principios básicos de la teoría publicitaria (Puig, 1986). En el tránsito al nuevo siglo, la publicidad se convirtió en un importante elemento de la economía que, además de ofrecer información acerca de los productos que podían ser adquiridos en los mercados, promocionaba la modernidad y educaba al consumidor en una nueva y amplia ideología de la 'obsolescencia estilística' (Marchand, 1985, p. 156), fenómeno que le obligaba a sustituir continuamente un producto por otro más actual.

Estados Unidos fue el país en el que el tránsito de una sociedad a otra se produjo con más fuerza. El paso del capitalismo de producción al de consumo tuvo lugar en este país entre 1890 y 1920 (Ewen, 1976). En Europa este proceso fue más lento a causa de los distintos conflictos bélicos que sacudieron el continente durante este período. En España la transformación social fue aún más tardía y no se produjo casi hasta mediados del siglo XX. El predominio de una sociedad agraria y el estallido de la Guerra Civil fueron las causas principales de este retraso.

Pero en todos estos lugares, con mercados más fuertes o más débiles, la linterna mágica colaboró con la publicidad para fomentar la nueva sociedad de consumo que iba a terminar por instaurarse en todo Occidente. La evolución de un sistema a otro, de un capitalismo de producción a un capitalismo de consumo, coincidió, en el tiempo, con la industrialización y venta en serie de las linternas mágicas y, posteriormente, con su declive y sustitución por los espectáculos cinematográficos. Javier Frutos y Carmen López, que han estudiado ampliamente este fenómeno, sostienen que en este período existía «un mercado de artefactos plenamente desarrollado» por el que «las sesiones de linterna mágica -ya fueran públicas o privadas- se convirtieron en una actividad industrial enormemente fértil y muy diversificada» (Frutos y López, 2010, p. 27). Fue el éxito y la difusión de este espectáculo el que hizo que se convirtiese en un espacio excelente para la comunicación publicitaria.

Durante el período que estamos abordando, la publicidad demostró ser una herramienta esencial para la promoción de los productos, pero enseguida se puso de manifiesto que las páginas de los periódicos y las paredes de las ciudades, soportes habituales en aquella época para publicar anuncios, eran insuficientes para cubrir la demanda de un número cada vez mayor de anunciantes. Era necesario buscar nuevos medios para la comunicación comercial y en ese contexto aparecieron los hombresanuncio, los vehículos publicitarios y las columnas móviles (Eguizábal, 1998, p. 145). A esta lista hay que sumar la linterna de proyección, que se utilizó para promocionar bienes y servicios mediante exhibiciones en las calles de las principales ciudades de Europa y Estados Unidos.

La referencia más antigua de la que tenemos constancia en este sentido nos lleva hasta 1868. El 7 de abril de ese año un tal Lefebvre-Duruflé, afincado en la calle Vaugirard de París, patentó un aparato para la «aplicación de la linterna mágica a la publicidad por medio de un foco luminoso» (LefebvreDuruflé, 1868). El nombre de Lefevre aparecerá más adelante en otras patentes similares registradas en Inglaterra y recogidas por Hermann Hetch en su libro Pre-Cinema History (1993). Es precisamente en esta obra donde localizamos la segunda referencia documental que nos habla de proyecciones publicitarias de linterna mágica. Se trata de una patente presentada en Inglaterra por J. M. A. Lacomme el 8 de agosto de 1870 en la que se describe una linterna concebida para «la exhibición de vistas publici-

Ediciones Universidad de Salamanca / CC BY - NC ND $\quad$ Fonseca, Journal of Communication, n. 16, 2018, pp. 11-30 
tarias o fotográficas» (Hetch, 1993, p. 164). En ella las placas podían insertarse una a una o quedar montadas en un mecanismo circular que, con la ayuda de un temporizador, giraba para cambiar la imagen expuesta cada cierto tiempo. Lancomme proponía que se ubicasen una o dos linternas en una habitación con el haz de luz dirigido hacia el exterior. Para recoger la imagen se instalarían sendas pantallas en la calle, formando ángulo recto con la pared e imitando los letreros y las señales de los comercios. El inventor sugería, a su vez, que se instalasen una pantalla y un proyector en un vehículo para que, de este modo, la publicidad viajase de un lado a otro de la ciudad. Por último, proponía que se utilizase su invento para proyectar las imágenes sobre las fachadas de los teatros y de los edificios dedicados a espectáculos de variedades. Las sugerencias de Lancomme recogían en una sola patente, y en una época muy temprana, los distintos procedimientos que los anunciantes pusieron en práctica en las calles europeas a lo largo de las décadas siguientes.

Sin duda, esta propuesta respondía a una inquietud colectiva que los inventores de la época estaban tratando de solucionar y que dio lugar a un amplio número de patentes de artilugios similares. Hetch recoge en su obra al menos 16 patentes que mejoraban en pequeños aspectos las proyecciones publicitarias de finales del siglo XIX. Varias de ellas fueron estudiadas por Stephen Herbert en un texto titulado 'Lanterns for Advertising' en el que se incluye una ilustración de la linterna propuesta por Lancomme (Herbert, 1997, p. 80). Como resultado de todas estas iniciativas se fabricaron equipos que proyectaron imágenes publicitarias en las calles de varias ciudades de Europa y Estados Unidos. Algunas de estas proyecciones quedaron recogidas, casi de manera anecdótica, en la prensa de la época. La noticia más antigua que conocemos aparece citada en la Enciclopaedia of the Magic Lantern (Robinson, et al., 2001, p. 10), y nos lleva hasta el 31 de agosto de 1870. Ese día el periódico The Times publicó un artículo titulado 'Sketches from Paris' en el que se citaba el uso de una linterna mágica para la proyección de imágenes publicitarias en un escaparate de la capital francesa.

El sistema debió de extenderse rápidamente a otros países, porque cinco años más tarde, en noviembre de 1875, Joaquín de Ariza y Carbonell presentaba en Madrid la solicitud de un Privilegio de Introducción de un procedimiento para «dar publicidad a los anuncios» por medio de la linterna mágica, tal y como se hacía en Estados Unidos (Ariza, 1875). De momento, este es el documento más antiguo que hemos localizado en relación a la utilización de la linterna mágica para usos publicitarios en España. En el expediente de esta solicitud se describen con todo detalle la linterna y el procedimiento. Y, a pesar de que no solicitaba patente para el equipo, Joaquín de Ariza incluyó un plano de la instalación (figura 1).

El objeto que se propone D. Joaquín de Ariza y Carbonell, es introducir en España el sistema establecido en los Estados Unidos de América, para dar publicidad a los anuncios que se le encarguen, por medio de una linterna mágica poderosa, alumbrada con la luz Drumond, haciendo aparecer los letreros sobre una gran pantalla transparente, colocada en algún sitio público, e intercalando entre anuncio y anuncio, figuras de movimiento, retratos de personajes célebres, monumentos artísticos, a fin de llamar más la atención y al mismo tiempo proporcionar al público un rato de agradable entretenimiento.

No se pretende el privilegio de introducción para el Estereopticón o linterna mágica perfeccionada y alumbrada con la luz Drumond, sino para el sistema de anuncios. (Ariza, 1875). 
Figura 1. 1875. Privilegio de Introducción 5370. Joaquín de Ariza y Carbonell

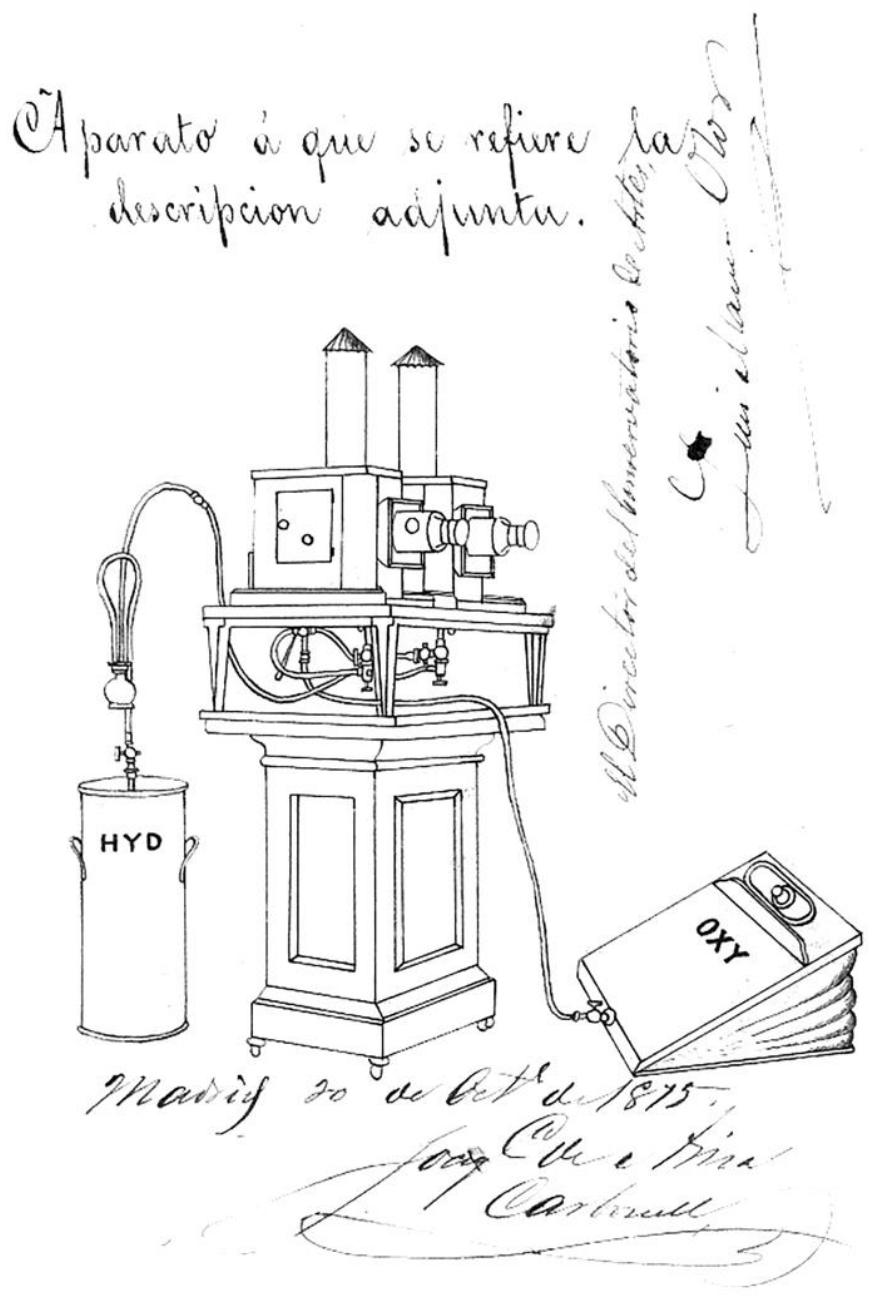

Fuente: Archivo Histórico de la Oficina Española de Patentes y Marcas.

Ariza inició el procedimiento el 02 de noviembre de 1875, pero el expediente se dio por cerrado el 10 de marzo de 1876 porque no se habían completado los trámites y no se habían pagado las 750 pesetas que costaba el otorgamiento del privilegio para un período de cinco años. Encontramos un posible motivo de este desistimiento en un texto de María del Carmen Simón Palmer en el que se recoge la negativa del Ayuntamiento de Madrid a autorizar el nuevo sistema de anuncios.

El día 1 de febrero de 1876 don Joaquín de Ariza, que había obtenido el privilegio de introducción por cinco años, solicitó licencia para establecer en la Puerta del Sol o en un lugar similar un quiosco. El Ayuntamiento desestimó la petición alegando que la vía pública debía estar siempre libre y desembarazada al tránsito. (Simón, 1977, p. 343). 
Entendemos que Joaquín de Ariza no concluyó el procedimiento por no haber conseguido las licencias oportunas del Ayuntamiento de Madrid. Sin previsión de ingresar dinero por la exhibición de anuncios, no tenía sentido pagar la alta cantidad que se le solicitaba para adquirir el privilegio. Simón Palmer hace referencia a una iniciativa similar presentada cinco años más tarde por Fermín Berasategui en el mismo ayuntamiento, pero «también en esta ocasión el Arquitecto Municipal informó en contra del permiso» (Simón, 1977, p. 344).

La ocupación de la vía pública y el entorpecimiento del tráfico fueron, precisamente, una de las causas por las que las proyecciones publicitarias de linterna mágica aparecieron en los periódicos. En nuestra búsqueda de información hemos encontrado varias noticias relacionadas con este aspecto. La más antigua nos la ofrece Steven Humphries, que cuenta cómo en 1876 el periódico The Globe publicó la noticia de que el tráfico de la calle Strand de Londres se había detenido ante la exhibición de una serie de cuadros disolventes. Según el artículo, las imágenes eran facsímiles de los carteles que podían verse habitualmente en la ciudad (Humphries, 1989, p. 122).

Otro de los motivos que llevaron las proyecciones publicitarias de linterna a los periódicos fueron las causas judiciales. El 26 de octubre de 1876 el South Walles Daily News, en el apartado de sucesos de Cardiff, hacía pública una sentencia que resolvía un caso en el que un ciudadano le exigía a otro la cantidad de 24 libras por el alquiler de una habitación en la calle Queen que iba a ser utilizada para proyectar publicidad por medio de la linterna mágica. La defensa alegaba que no había rentas pendientes porque ambos litigantes eran socios de este «magic lantern advertising business» (District, 1876).

Unos años más tarde, el 26 de enero de 1883, el Edinburgh Evening News publicaba una nota de prensa titulada 'Advertising by Magic Lantern' que recogía la consulta jurídica que un vecino de Londres había presentado el día anterior en la Street Police Court (Advertising, 1883). En ella el solicitante, un fabricante de calzado, contaba que tenía un negocio en Tottenham Court Road. Su vecino era sastre y últimamente había empezado a proyectar cuadros disolventes por medio de una linterna mágica desde el segundo piso de su establecimiento. Este hecho atraía a una gran cantidad de gente que se quedaba a ver las imágenes, quietos frente al escaparate del zapatero, y no dejaban pasar a sus clientes. La policía había intervenido y había llamado la atención al sastre, pero sin efecto alguno. El asesor jurídico contestaba que había un precedente, ocurrido unos años antes, en el que se recogía una queja similar presentada contra un famoso relojero de la ciudad. Su consejo era que se reuniesen varios vecinos afectados por este hecho y presentasen una demanda común.

Las quejas vecinales y la intervención de la policía en proyecciones publicitarias de linterna mágica llegaron también a París. En la sección de sucesos del periódico Gil Blas del 13 de abril de 1887 leemos:

La préfecture de pólice, qui a interdit dernierement la publicité lumineuse que l'on faisait circuler dans les rues, ferait bien d'interdire la lanterne magique réclame qui est placée près du théâtre des Veriétés. Les badaus qui, chaque soir, s'arrêtent prês du passage Jouffroy, pour voir cette publicité lumineuse encombrent tellement le trottoir qu'il est absolutement imposible de circuler. (Nouvelles, 1887, p. 1).

El año y el lugar, 1887 en el Passage Jouffroy, podrían estar relacionados con una referencia que aparece en el volumen 9 de la publicación Lanterna Magica, publicada en Düsseldorf en 1887 y citada por Hetch (1993, p. 211). En dicho texto se habla de la proyección de anuncios publicitarios en el Boulevard Montmartre de París, intercalados con imágenes humorísticas y vistas de lugares. 
Curiosamente, en la prensa española aún no hemos conseguido recuperar ninguna referencia que hable de proyecciones publicitarias de linterna en nuestro país, pero sí que hemos encontrado noticias en las que se informaba del desarrollo de esta actividad en otros lugares del mundo. El 24 de septiembre de 1888, por ejemplo, el colaborador de La Vanguardia Luis de Llanos enviaba una 'Carta desde Bruselas' en la que contaba que, de camino a Flandes, había decidido pasar una noche en París. En un tono bastante crítico, que le servía para describir una ciudad «decadente», «pobre» y «nada acogedora», comentaba:

\begin{abstract}
Ahora la gran moda es anunciar de noche con linternas mágicas. En un gran paredón del boulevard aparece una gran vista del Cairo, luego otra del Partenón de Atenas, luego otra del patio de las muñecas de Sevilla, y cuando ya está la calle negra de curiosos empiezan a aparecer anuncios de tamaño colosal de todo género de drogas o de publicaciones periódicas. Cuando el público -al que le han obligado a leer a pesar suyo- comienza a desfilar, la linterna lanza de nuevo sobre el muro imágenes [...]. La función se repite muchas veces. (Llanos, 1888, p. 1).
\end{abstract}

La utilización de la linterna mágica como soporte publicitario debía de ser algo habitual en las calles de las principales ciudades de Europa, tanto que se colaba en reportajes y relatos que nada tenían que ver con la propia linterna. El 2 de marzo de 1889, por ejemplo, la linterna aparecía de manera casual en una noticia que relataba la disolución de la Liga de los Patriotas, grupo de la extrema derecha francesa. En la crónica, publicada en La Lanterne: journal politique quotidien, se hablaba de distintos hechos acontecidos a lo largo del día. Al describir los sucesos de la tarde el periodista comentaba:

\begin{abstract}
Quelques groupes ont stationné devant les bureaux du journal de M. Laguérre. C'étaient des curieux, arrètés par lanternes magiques réclame qui attire chaque soir les badauds sur centains points du boulevard. Les rassemblements se sont rapidement dissipés. Et vers onze heures, le dernier curieux avait disparu. (Ligue, 1889, p. 1).
\end{abstract}

\title{
3. NUEVOS ESCENARIOS PARA LA PROYECCIÓN DE ANUNCIOS: 1887-1895
}

La proyección de placas publicitarias de linterna mágica dio lugar a empresas específicas dedicadas a esta actividad. Hetch cita la creación en Frankfurt, en el año 1887, de la Magic Lantern Advertising Company, dedicada a la comercialización de placas publicitarias que se alternaban con cuadros disolventes (Hetch, 1993, p. 211). Dos años después, en septiembre de 1889, Wilkinson \& Co., fabricante de linternas y placas, envió al Optical Magic Lantern Journal and Photographic Enlarger una carta en la que planteaba la oportunidad de ampliar este sector y de crear una agencia que centralizase la fabricación y distribución de placas publicitarias. La agencia contaría con sucursales en las ciudades más importantes del país y sería la responsable de los contratos con los anunciantes. La propia Wilkinson \& Co. se ofrecía a llevar a cabo estas tareas (Hetch, 1993, p. 223).

En este mismo período, la proyección de imágenes publicitarias se instaló en las estaciones de trenes, lugares privilegiados para la exhibición de carteles. Humphries cita un reportaje publicado en 1889 en The Optical Magic Lantern Journal en el que se comenta que las principales estaciones de Gran Bretaña contaban con sistemas de proyección de publicidad con linternas mágicas. Los anuncios promocionaban la propia compañía y mostraban imágenes de trenes y paisajes que cambiaban, cada treinta segundos, gracias a la automatización del mecanismo de la linterna (Humphries, 1989, p. 122). 
La primera referencia documentada de proyección de placas publicitarias en los telones de los teatros, durante los descansos de las representaciones, sitúa el inicio de esta práctica en Londres y en el año 1893 (Hetch, 1993, p. 405). Nosotros tenemos una referencia anterior que ubica esta práctica en España, pero no sabemos si la iniciativa llegó a realizarse. El 12 de julio de 1892 Fernando Márquez y Anglada presentó en Madrid una solicitud de patente de invención de «un procedimiento para anuncios luminosos en los telones de los teatros». La memoria en la que se desarrollaba el procedimiento especificaba que, durante los entreactos de las representaciones de los teatros «se echará un telón de lienzo en blanco» $y$, "por medio de una linterna mágica $[. .$.$] se proyectarán sobre el telón cuadros$ disolventes $[\ldots]$ alternando con otros en que vayan impresos letreros o rótulos de anuncios» (Márquez, 1892). Según consta en el expediente de esa solicitud, la patente se concedió el 26 de julio de ese mismo año, pero no se comunicó su puesta en práctica.

Humphries comenta que era habitual que se proyectase publicidad en estos espacios y alude a una serie de cartas en las que los anunciantes se quejaban porque las placas se exhibían antes de que llegasen los espectadores de las butacas más caras e, incluso, antes de que las puertas se abriesen al público (Humphries, 1989, p. 122). No eran estas las únicas quejas que llegaban a la prensa. Al parecer, los anunciantes ofrecían sus placas de manera gratuita a cambio de que los proyeccionistas enviasen informes regulares con datos acerca de la frecuencia con la que se utilizaban las imágenes, las personas que asistían a las proyecciones y el estatus social del público. Con esta información, los anunciantes intentaban elaborar unos incipientes estudios de mercado. A los linternistas, sin embargo, no les hacía ninguna gracia cumplir con su parte del trato y enviaban quejas al The Optical Magic Lantern Journal para protestar por las exigencias de los anunciantes (Humphries, 1989, p. 127).

Las cartas recibidas en la citada publicación revelaban, a su vez, usos inesperados de las placas publicitarias de linterna mágica. En el año 1893 un predicador evangélico que utilizaba la linterna mágica en sus charlas sobre sobre moral y abstinencia, envió una carta al periódico en la que decía:

I may say that when I exhibit advertisements slides I always try and point a moral and tell a tale. With 'The Cabby and his Cocoa' (Cabury's) I say 'far better to drink cocoa than beer, he is more likely to have his head clear and his feet warm'; with 'Matchless Cleanser' that 'Cleanliness is next to Godliness and if more soap were used there would be less dirt and so on morally'. So you see it is possible to make even this class of advertisement really instructive if pains be taken. (Humphries, 1989, p. 127).

De nuevo en España, el 13 de septiembre 1893, Onofre Valldecabres Pechuán, vecino de Valencia, presentó en Madrid una solicitud de patente de invención que proponía la utilización de la linterna mágica para usos publicitarios. Esta solicitud se limitaba a reclamar el uso de «el aparato de la linterna y demás aparatos ópticos que sirven para proyectar imágenes sobre cualesquiera superficies, al objeto de poder utilizar tales aparatos en la publicación de anuncios» (Valldecabres, 1893). La propuesta, que no ofrecía ninguna novedad aparente, es de gran importancia para nuestra investigación porque es, hasta el momento, la primera referencia documentada del uso práctico de la linterna para la proyección de anuncios en nuestro país. El expediente de esta patente incluye un documento anexo en el que el interesado, con fecha 14 de octubre de 1895, acredita que «en la ciudad de Valencia, calle de Ángeles n. 1, domicilio de D. Elías Martínez Lechón, se ha puesto en práctica de explotación el objeto sobre el que recayó la patente de invención 14.944» (Valldecabres, 1893). No tenemos más información al respecto. 
Mientras tanto, en enero de 1894 y en la ciudad de Nueva York, las proyecciones publicitarias de linterna mágica daban un paso más y elegían las nubes como pantalla. Este hecho trascendió el ámbito local y llegó a aparecer en la prensa española. El sábado 27 de enero de 1894, en la primera página de El correo Español, podía leerse:

Los habitantes de Nueva York han tenido una verdadera sorpresa la otra noche al ver dibujarse en las nubes una leyenda que, lejos de ser algo parecido a la fatídica del banquete de Baltasar, se reducía simplemente a encomiar la superioridad de cierto periódico diario y a recomendar a todos que lo compraran, porque sólo cuesta tantos centavos. El principio en el que se funda este resultado es sencillo [...]. Es el principio de la linterna mágica, sólo que se trata de una linterna enorme, cuyo foco luminoso posee, según se dice, la potencia de más de un millón de bujías, y que se sirve de las nubes como de una tela para reproducir o pintar en ellas las imágenes de los objetos. El aparato lleva el nombre de cloud proyector (proyector sobre nubes), denominación que indica con bastante claridad su naturaleza. (Olaeta, 1894, p. 1).

Hetch también recoge en su obra un acontecimiento datado en 1894 en el que el New York Times proyectó publicidad en las nubes (Hetch, 1993, p. 405). Podría tratarse del mismo evento. Un año más tarde, el periodista José Echegaray hacía referencia a un fenómeno similar en El Liberal del jueves 23 de mayo de 1895. En un artículo titulado 'Crónica científica: dos inventos novísimos', el autor describía un invento parecido al cloud projector y un sistema para evitar naufragios. Sobre el primero, que es el que a nosotros nos interesa, el autor decía:

Pues he aquí que, agotadas todas las superficies y todos los medios de publicidad, se ha ocurrido recientemente ir a fijar anuncios en el cielo, o si no en el cielo, un poco más abajo, en las nubes que flotan por la atmósfera. [...] Este nuevo invento, este sistema de publicidad en las nubes, data de la Exposición de Chicago $^{1}$, donde todas las noches un proyector eléctrico fijaba en el cielo nebuloso el número de personas que habían visitado la Exposición durante el día. Y una vez ocurrida esta idea, parece la idea más sencilla y más natural del mundo. Es la linterna mágica en grande escala, con un lienzo o una sábana inmensa tendida allá en el espacio. (Echegaray, 1895, p. 1).

En el archivo histórico del New York Times no hemos conseguido localizar ninguna referencia a esta proyección a pesar de que, curiosamente, dos años antes el periódico publicó una noticia titulada 'Writing on the clouds' en la que hablaba del éxito de dos experimentos realizados en Inglaterra para proyectar publicidad en las nubes (Writing, 1892). La primera demostración se había realizado en Londres y su artífice había sido el capitán Ronald Scott. La segunda había corrido a cargo de Sydney Hodges en la ciudad de Ealing. El artículo incluía las opiniones de varios científicos norteamericanos que explicaban la factibilidad técnica del procedimiento.

En el mes de marzo de 1895 Alfred Cecil Wright, vecino de Birmingham, presentó en Madrid una solicitud de patente para registrar en España su invento de «un sistema de linterna para anuncios»

\footnotetext{
${ }^{1}$ Celebrada en 1893
} 
(Wright, 1895). La memoria describe al detalle, con la ayuda de un plano, las características de la linterna que el autor afirmaba utilizar para proyectar anuncios (figura 2).

Figura 2. 1895. Patente de Invención 17119. Alfred Cecil Wright

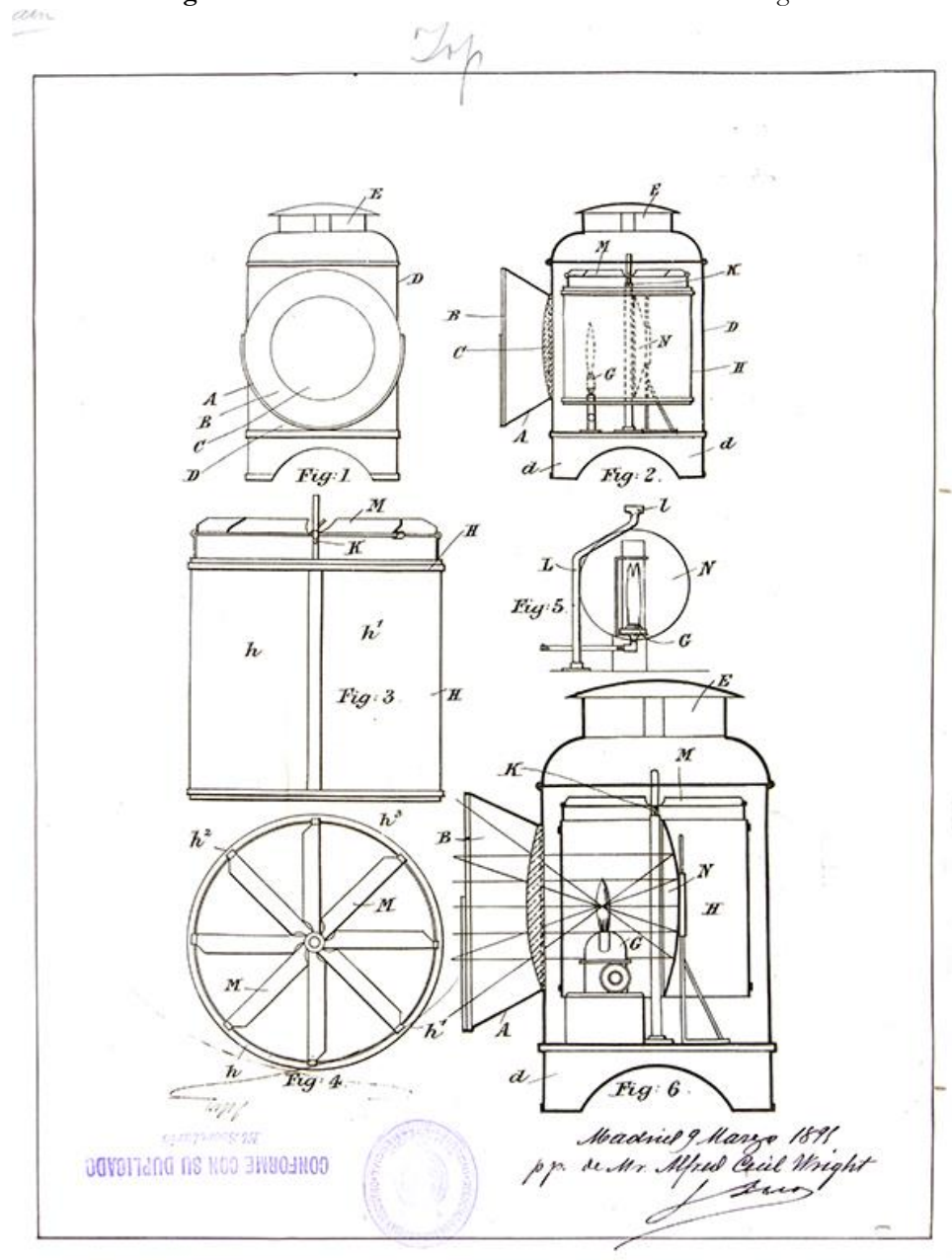

Fuente: Archivo Histórico de la Oficina Española de Patentes y Marcas.

A lo largo de ese mismo año se proyectaron placas publicitarias de linterna en el País Vasco. Cuenta José María Unsaín, en el libro El cine y los vascos, que en el año 1895 el empresario Carlos San Gregorio, propietario de los almacenes Ville de Paris de Bilbao, anunciaba su establecimiento en la calle Correo mediante la proyección de placas publicitarias de linterna mágica (Unsaín, 1985, pp. 35-36).

En algunas ocasiones los anunciantes eligieron mal sus 'pantallas' y eso les llevó a recibir severas críticas. Hetch cita algunas de ellas y comenta las protestas que despertaron las proyecciones publicitarias que se realizaron en el Monumento a Nelson y en la pared exterior de una iglesia de Londres en 1895 (Hetch, 1993, p. 405).

En diciembre de 1895 los hermanos Lumière presentaban el cinematógrafo en la ciudad de París. 


\section{LAS PROYECCIONES PUBLICITARIAS DE LINTERNA MÁGICA TRAS LA INVEN- CIÓN DEL CINEMATÓGRAFO. 1895-1920}

El cinematógrafo se integró rápidamente en la lista de los medios que exhibían anuncios, pero no desplazó el uso de la linterna mágica como soporte publicitario (Sánchez, 2010). Por el contrario, ambos medios convivieron desde el principio y mezclaron sus mensajes y contenidos. Hemos localizado algunas referencias que nos hablan de esta convivencia desde fechas muy tempranas. En diciembre de 1897, en la 'Crónica Parisiense' que Antonio Ambrona firmaba en El álbum americano, se leía:

\footnotetext{
Frente a nosotros, en la fachada de Variedades, una serie de vistas cinematográficas llaman la atención de una numerosa muchedumbre que aplaude aquel progreso científico, aquella reproducción fotográfica de la vida: el color y el movimiento.

Pero, de tiempo en tiempo, el cinematógrafo cede su puesto a la linterna mágica y grandes anuncios luminosos reemplazan a las placas fotográficas. El público aplaude. El público se ha tragado el anuncio, que es lo que se trataba de demostrar. (Ambrona, 1897, p. 555).
}

A pesar de que todo indica que en Europa las proyecciones publicitarias eran algo habitual, en España debían de ser aún poco conocidas, porque en mayo de 1897 volvió a presentarse una patente en la que su autor, el sevillano Leopoldo Murga Machado, comentaba que había «tenido ocasión de ver y apreciar las incansables ventajas que en el extranjero se alcanzan con el sistema de anuncios fotográficos por medio de la linterna de proyección» y quería que España contase con un sistema «sin explotar todavía entre nosotros» (Murga, 1897). En el expediente de la solicitud consta que esta patente no llegó a cursarse.

Poco después, en noviembre de 1899, José Toll presentaba en Barcelona una nueva solicitud de patente de invención para utilizar un sistema de proyección con fines publicitarios. Según consta en el resumen del expediente, se trataba de un «procedimiento mecánico para la exhibición de anuncios proyectados lumínicamente y combinados con la exhibición de proyecciones luminosas animadas alternadas con otras fijas» (Toll, 1899). Esta referencia es de gran importancia porque se comunicó oficialmente que el sistema se había puesto en práctica el 19 de febrero de 1902. No hemos podido constatar el lugar, ni tampoco obtener la descripción del procedimiento, porque el expediente original está muy deteriorado y no se puede consultar. Tampoco hemos podido verificar si las "proyecciones animadas» de las que se habla hacen referencia a imágenes cinematográficas o a cuadros disolventes.

En marzo de 1899 volvía a aparecer en la prensa británica una noticia legal en la que se resumían cuatro causas abiertas contra un agente de publicidad, Horace Christopher Crow, acusado de colapsar el tráfico en las calles de Manchester con proyecciones cómicas y publicitarias de linterna mágica. Las imágenes congregaban a tantos curiosos que los espectadores se veían obligados a ocupar la calzada e impedían el paso de los vehículos. El acusado reconocía los hechos y, para resolver el caso, se ofrecía a solicitar la asistencia de la policía en el caso de que volviese a congregarse un grupo numeroso de espectadores. La interrupción de la proyección solo se planteaba como último recurso (Obstruction, 1899).

Llegados ya al siglo XX el cinematógrafo empezó a sustituir a las linternas mágicas en casi todos sus usos y manifestaciones, incluido el publicitario. A pesar de ello, las linternas se mantuvieron vivas durante mucho tiempo y evolucionaron para dar lugar a un soporte específico, el de las 'diapositivas publicitarias', que estuvo vigente durante varias décadas. A partir de este momento resulta casi imposible distinguir un sistema de otro o averiguar qué cristales se exhibieron con linternas mágicas y qué 
otros se lanzaron desde el propio equipo de proyección cinematográfica, al que se le acoplaba un dispositivo móvil que permitía alojar filtros de colores, placas de linterna y anuncios.

Existen algunas referencias claras, como las aportadas por Santos Zunzunegui, que en el libro El cine en el País V asco habla específicamente del uso publicitario de la linterna mágica en dos ocasiones. El 16 de mayo de 1905 Nicolás Zulueta presentó en el Ayuntamiento de Bilbao una solicitud en la que pedía autorización para proyectar vistas fijas en la Zapatería de Madrid, que estaba ubicada en la calle de los Fueros. Dos años después, en 1907, el Café Olimpia proyectaba imágenes sobre una pantalla ubicada en su tejado (Zunzunegui, 1995, pp. 17-18).

En otros casos no sabemos con exactitud qué equipos se utilizaron. Desde el año 1901, las solicitudes que se presentaron en España para intentar patentar el procedimiento de la proyección de anuncios incluían ambos sistemas. Ocurre así, por ejemplo, en la solicitud presentada en Madrid el 9 de septiembre de 1901 por Rafael Marín, que intentó patentar «un procedimiento de anuncios portátiles, en toda clase de colores y figuras, empleando para ello la linterna mágica, el cinematógrafo y toda clase de aparatos que tiendan a aumentar los objetos» (Marín, 1901). La memoria proponía que un hombre llevase al hombro cualquiera de estos equipos y proyectase los anuncios en un cuadrado de tela, en las paredes de las casas o en el suelo. Por extraño que pueda parecer, la idea de que un hombre cargase con una linterna mágica publicitaria a sus espaldas ya se había patentado en Inglaterra en el año 1896 (Herbert, 1997, p. 85). En nuestro país esta solicitud fue desestimada y, sin embargo, la descripción del sistema coincide con la fórmula del «hombre-sandwich cartel-cinematográfico» que los teóricos Bori y Gardó incluyeron en su repaso de los medios publicitarios disponibles a finales de la década de los 20. En la primera edición de su Manual práctico de publicidad ya describían un procedimiento que consistía en:

una pantalla en la que por un aparato que el hombre lleva a la espalda va proyectando diversos anuncios [...]. No es mucha su visibilidad amortiguando el efecto la iluminación de la calle, razón por la que no se ha empleado con mayor frecuencia retirándose al poco tiempo. (Bori y Gardón, 1928, vol. II, p. 100).

En las dos primeras décadas del siglo XX se presentaron otras patentes que también fueron desestimadas y en las que no nos vamos a detener. En todos los casos se intentaba patentar la proyección publicitaria sin aportar novedades técnicas o equipos específicos.

En la que sí que merece la pena detenerse es en la solicitud de patente de invención presentada en Barcelona en septiembre de 1905 por Ángel Fernández Alfageme. La memoria de este invento propone «la explotación de un sistema especial de anuncios realizados por medio de proyecciones luminosas» que nos recuerda a la patente presentada por Lancomme en Inglaterra en 1870. El autor reconoce que ya «se utilizan aparatos y procedimientos análogos» con este fin y comenta que la nueva linterna presenta la «particularidad y novedad» de que «las proyecciones cambian o se renuevan automáticamente sin necesitar durante varios días cuidado ni manipulación alguna» (Fernández, 1905). Para ello, el inventor propone que los cristales se monten formando un círculo en una rueda giratoria conectada a un aparato de relojería encargado de mover la rueda a intervalos regulares (figura 3). Estas características se encontraban ya en la patente de Lancomme (Herbert, 1997, p. 80).

De nuevo, el expediente de la solicitud nos dice que el invento no se puso en práctica, pero también de nuevo encontramos una descripción similar en las publicaciones de los teóricos Bori y Gardó, esta vez en la última edición del Tratado completo de Publicidad y Propaganda. En la tercera edición de su obra, revisada en el año 1936, los autores se detenían por primera vez en la proyección de imágenes 
publicitarias fijas y citaban varios sistemas posibles, entre ellos el de un «disco» o una «rueda en la que están montados los cristales» (Bori y Gardó, 1936, p. 603). Estos autores, pioneros del estudio de la publicidad en España, no prestaron atención a la proyección de anuncios fijos hasta la tercera edición de su libro y solo como introducción a un capítulo dedicado a la publicidad cinematográfica. En la segunda edición de su obra, actualizada en el año 1931, citaban este soporte solo de pasada al comentar que «hay publicidad de proyección de anuncios» que «no pueden considerarse más que como la proyección de un cartel» (Bori y Gardón, 1931, p. 457). Curiosamente, los anuncios cinematográficos, lo que ellos denominaban "publicidad por el film», sí aparecían citados en la primera edición de su obra (Bori y Gardó, 1928, vol. I, p. 30). Este hecho hace pensar que las linternas mágicas tuvieron poco éxito en España como soporte publicitario.

Figura 3. 1905. Patente de Invención 36742. Angel Fernández Alfageme
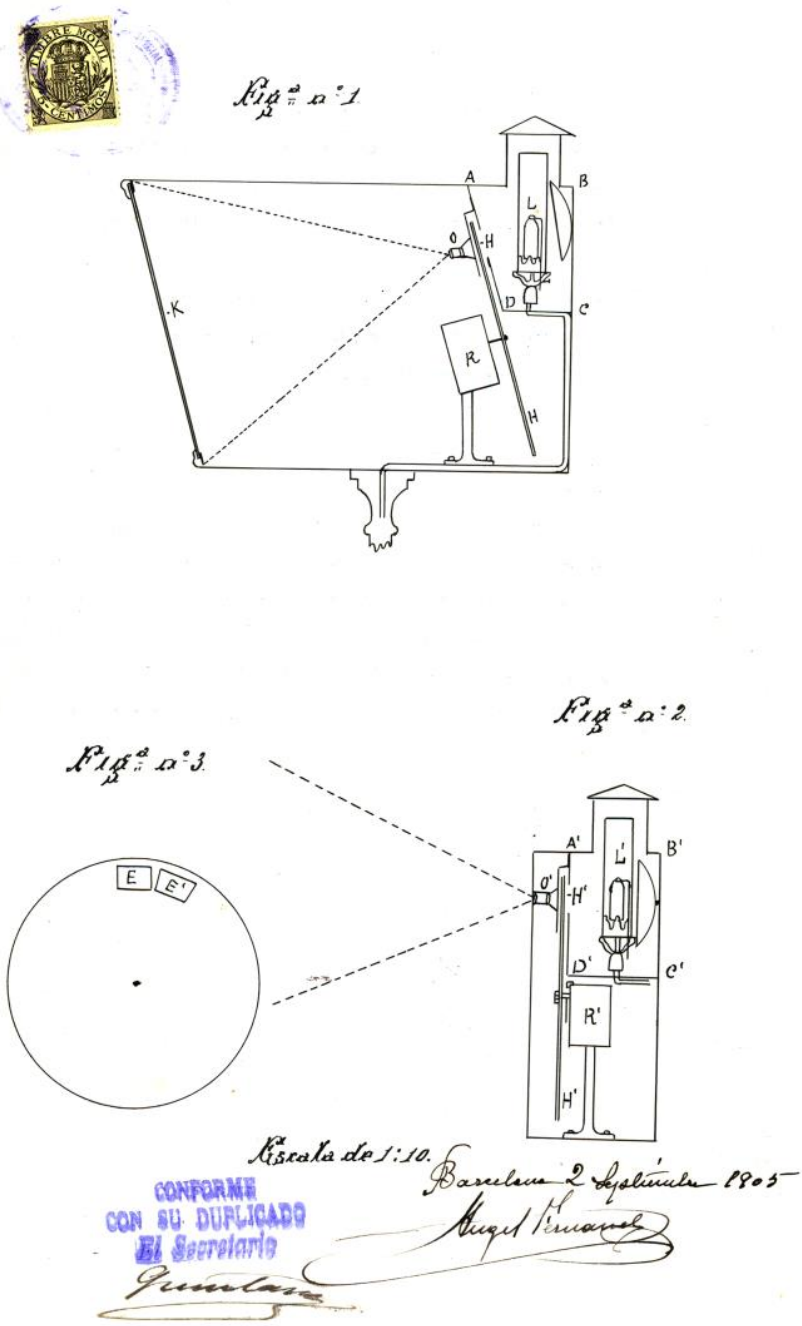

Fuente: Archivo Histórico de la Oficina Española de Patentes y Marcas. 
Sabemos que la linterna mágica se siguió utilizando como proyector publicitario durante las primeras décadas del siglo XX, pero hemos recuperado muy poca información que nos permita acercarnos al medio durante esos años. Necesitamos seguir buscando datos que nos hablen de este período en el que las linternas convivían con el cinematógrafo y se utilizaban para proyectar publicidad en los descansos de todo tipo de espectáculos. El cinematógrafo se impuso rápidamente como medio de comunicación de masas y dio lugar a nuevas propuestas narrativas con características propias. Los espectáculos de linterna fueron desapareciendo poco a poco y lo que sobrevivió fue el proyector, que quedó como acompañante y apoyo del cinematógrafo. Esa linterna mágica, convertida ya casi en un «proyector de diapositivas» eléctrico, se mantuvo activa en los escaparates de los comercios y en los descansos de otros espectáculos durante mucho tiempo, dedicada casi exclusivamente a la proyección de anuncios y avisos.

Entre los usos publicitarios de esa linterna, vista ya únicamente como proyector de imágenes fijas, se encuentra una curiosidad con la que vamos a dar fin a este repaso histórico. En junio de $1923 \mathrm{Vi-}$ cente Alonso Mercé y José Antonio García Cassola presentaron en Madrid una patente de invención sobre «el resultado industrial consistente en un anuncio luminoso obtenido por medio de una linterna de proyecciones colocada en los coches de los ferrocarriles y tranvías subterráneos, que proyectará los anuncios sobre los paramentos del túnel» (Alonso y García, 1923). La memoria del invento incluía un plano que indicaba dónde tenía que instalarse la linterna para que proyectase los anuncios en las paredes de los túneles del tranvía (figura 4). El expediente de la solicitud dice que el sistema nunca se llevó a la práctica, pero Bori y Gardó describen un sistema similar en la edición de 1931 de su Tratado de publicidad:

Recientemente se ha presentado otra modalidad utilizable únicamente en tranvías metropolitanos, que es la proyección de anuncios en las paredes del túnel, sin bien, dada la velocidad a la que circulan estos tranvías y su profusa iluminación interior, no es muy recomendable. (Bori y Gardó, 1931, p. 538).

No sabemos si estas iniciativas tuvieron un uso práctico en el entorno de la publicidad española. Unas referencias hacen pensar que sí y otras nos llevan a creer todo lo contrario. Es necesario seguir investigando para perfilar esta historia con mayor claridad. El recorrido por las anécdotas y referencias que hemos conseguido localizar nos ofrece una imagen difusa que se mueve a partes iguales entre lo cotidiano y lo anecdótico. Unas veces se habla de proyecciones publicitarias de linterna mágica con absoluta normalidad y otras se expone el invento como si se tratase de un auténtico delirio.

Hemos dejado para el final de este capítulo una cita en la que vemos un nuevo ejemplo de esa normalidad delirante que rodea el uso publicitario de las linternas mágicas. Se trata de unas palabras escritas por Gastón Leroux en 'La Mansarde en Or', folletín publicado en el periódico parisino Le Journal a lo largo de 1925. En el número del 11 de diciembre, en una descripción de las calles de Paris, dice así:

Cela formait un conglomérat informe, une agglutination de matériaux grossiers autour de cette vague image de lanterne magique qu'une publicité obstinée avait fait surgir dans l'obscurité opaque de leurs chambres crâniennes: Paris-la-Nuit! (Leroux, 1925). 
Figura 4. 1923. Patente de Invención 85998. Vicente Alonso Mercé y José Antonio García Cassola

\title{
Plano de la disposicion del anuncio
}

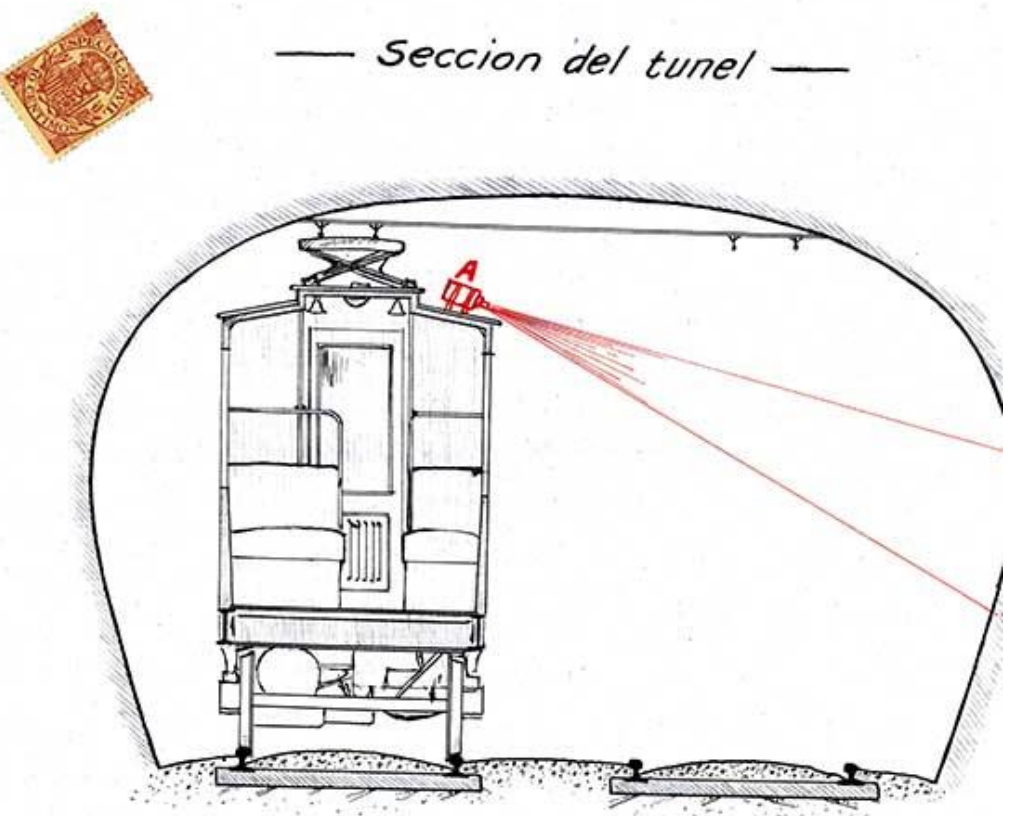

\author{
$A=$ Linterna de proyecciones \\ $B=$ Muro del tunel donde se proyecta el anuncio.
}

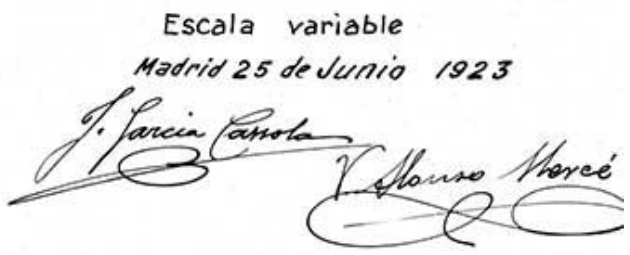

Fuente: Archivo Histórico de la Oficina Española de Patentes y Marcas.

\section{CONCLUSIONES}

Del análisis de las múltiples referencias que hemos localizado se deduce que la linterna mágica se utilizó como soporte de los mensajes publicitarios desde el último tercio del siglo XIX y que se mantuvo vigente hasta la segunda década del siglo XX. Una vez desaparecidos los espectáculos de linterna, los cristales publicitarios se desarrollaron para dar lugar a otro soporte específico, denominado «diapositivas publicitarias», que reunía características propias y que, como medio, estaba directamente vinculado con el público y el espacio cinematográficos. 
Los datos recogidos hacen pensar que la práctica de proyectar publicidad por medio de linternas mágicas era algo habitual en los países más industrializados. Esta actividad dio lugar a empresas subsidiarias y a incipientes estudios de consumo en países como Alemania y Reino Unido. En España, a pesar del intento de empresarios e inventores de imitar un modelo que estaba dando frutos en otros países de Europa, este nuevo medio no pareció despertar el interés de los anunciantes.

En una primera fase las proyecciones de linterna mágica funcionaron como medio de publicidad exterior, aunque de una forma mucho más elaborada de lo que pensábamos. Hace años, y en base a los primeros textos publicados sobre esta materia, creíamos que la linterna se había limitado a proyectar reproducciones de carteles publicitarios, pero las descripciones que hemos podido leer en las crónicas de los periódicos y en las memorias de los inventores muestran con claridad que la publicidad formaba parte de espectáculos más complejos en los que se atraía la atención del público con relatos e imágenes propias de las sesiones de linterna mágica. Los anuncios no eran los protagonistas y solo aparecían, de manera bien calculada, cuando el público estaba absorto contemplando otras imágenes.

Las proyecciones publicitarias en el contexto específico de las sesiones de linterna mágica no quedan documentadas hasta la década de 1890 y, en ese sentido, coinciden con el auge del propio espectáculo. Es ahí cuando la publicidad empieza a ocupar un espacio propio al inicio, en los descansos y al final de las representaciones.

Las proyecciones publicitarias de linterna mágica se insertaron también en los espectáculos teatrales y, en este caso, eligieron la misma fórmula que ofrecían en las calles: con sesiones de ocio y entretenimiento en las que los anuncios aparecían de manera intermitentemente.

De todo lo anterior se deduce que las linternas mágicas fueron el origen de la actual publicidad audiovisual, en la que los anuncios se intercalan con los programas de entretenimiento y en la que se trabaja para crean contenidos específicos en los que el relato acoja de manera natural el mensaje publicitario. El medio publicitario linterna-mágica se configura, por lo tanto, como un claro antecedente de los esquemas actuales de la publicidad del espectáculo.

Estas características resultan aún más evidentes cuando se analiza el contenido de las placas publicitarias de linterna mágica que aún se conservan. Esta línea de investigación, que hemos dejado intencionadamente fuera de este artículo, ofrece muchísimas posibilidades que iremos abordando en otros estudios.

Tampoco hemos abordado el estudio de otros sistemas ópticos utilizados en el siglo XIX como soporte publicitario. Su análisis puede dar lugar a interesantes resultados. No quedemos cerrar este artículo sin ofrecer un ejemplo. Recurrimos para ello a la solicitud de patente presentada en Barcelona en mayo de 1904 por José Barberá Humbert y Domingo Maña Solé, en la que proponían utilizar las imágenes estereoscópicas como vehículo publicitario (Barberá y Maña, 1904). Su mayor ventaja era, según sus inventores, la del coleccionismo, que iba a multiplicar la eficacia del anuncio a lo largo de los años (figura 5). No estaban equivocados porque el coleccionismo ha sido, precisamente, el que ha permitido que se conserven muchas de las imágenes y equipos que hoy estamos estudiando.

La linterna mágica y los aparatos ópticos de lo que conocemos como 'pre-cine' fueron la puerta de entrada a la modernidad. No se reconoce lo suficiente el importante papel que jugaron como vehículo de nuevas propuestas e ideologías. Lejos de ser meras curiosidades científicas, juguetes o experimentos, los equipos de proyección de imágenes marcaron el camino a todo un mundo de propuestas científicas, académicas, comerciales y políticas que configuraron los modelos económicos y sociales del siglo XX. Los textos que hemos repasado muestran las inquietudes de una sociedad que caminaba hacia el futuro y en la que la publicidad y el consumo aparecían como elementos configuradores de nuevos esquemas sociales. 
Figura 5. 1904. Patente de Invención 34022. José Barberá Humbert y Domingo Maña Solé
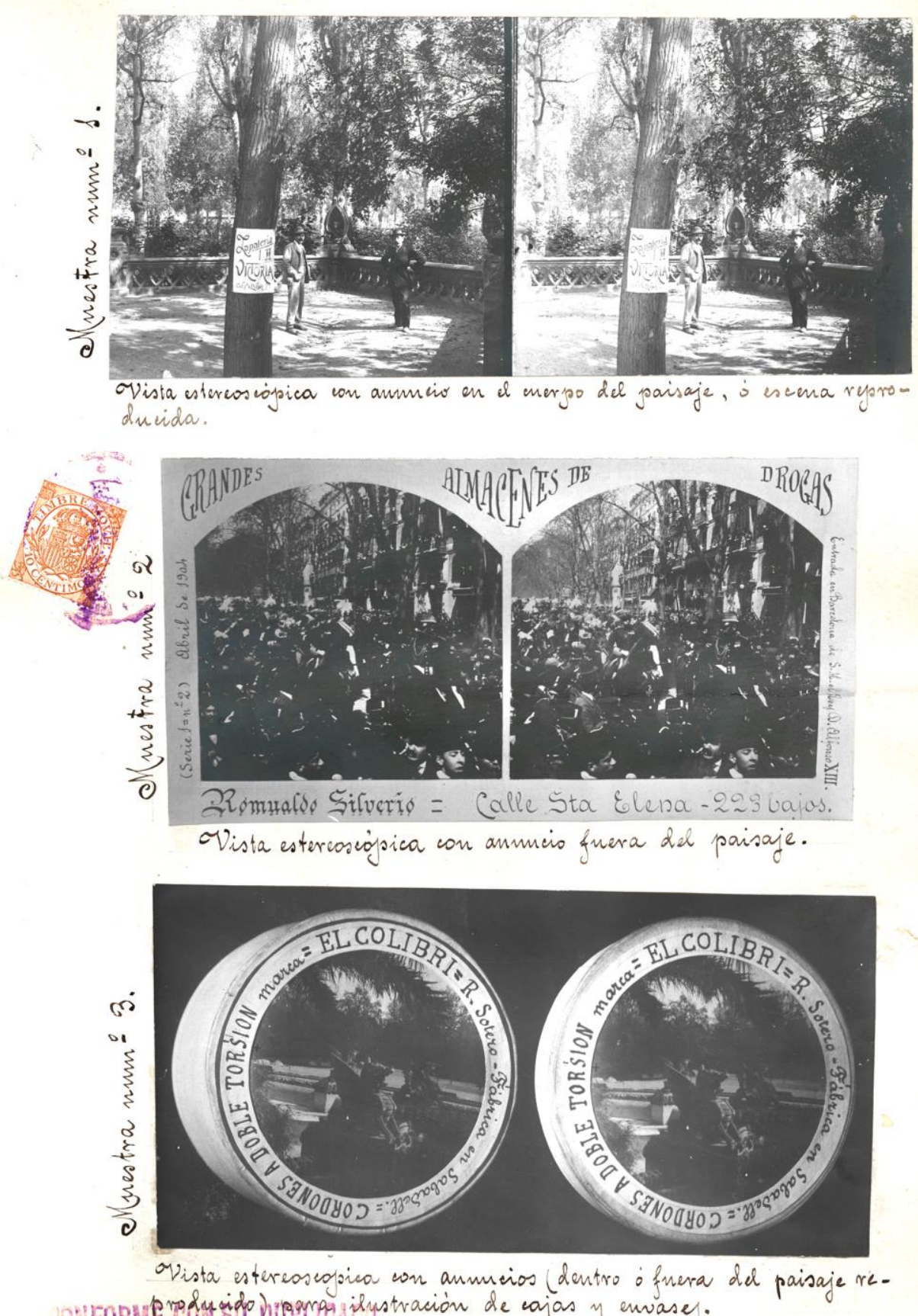

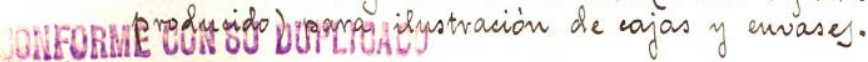

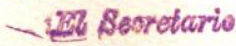

Fuente: Archivo Histórico de la Oficina Española de Patentes y Marcas. 
Para terminar, queremos invitar a los lectores a visitar los recursos on-line en los que se reproducen placas publicitarias de linterna mágica. Pueden localizarse algunos ejemplos en las las herramientas que el proyecto 'A Million Pictures' ha puesto en manos de los investigadores. En el repositorio 'Lucerna’2 y en la aplicación 'Linternauta'3, además de referencias bibliográficas adicionales, se pueden ver imágenes de cristales con contenido publicitario. Es altamente recomendable, por otro lado, visitar la web 'De Luikerwaal', gestionada por Henc R. A. de Roo y pionera en la difusión de la historia de la linterna mágica ${ }^{4}$. Los cristales publicitarios que recoge esta página son de una gran belleza.

En este texto nos hemos limitado a señalar hechos, fechas y referencias, pero el análisis pormenorizado de cada una de las referencias de nuestra bibliografía puede ofrecer muchas otras interpretaciones e ilustrar muchos otros puntos de vista. Confiamos en que alguno de estos datos sirva de inspiración para nuevas investigaciones y que este sea solo el inicio de un recorrido mucho más largo por las múltiples historias que todavía nos cuenta la linterna mágica.

\section{FUENTES CITADAS EN EL TEXTO}

Advertising (1883). Advertising by Magic Lantern. The Edinburgh Evening News. Friday January 26, $1883,4$.

Alonso Mercé, V. y García Cassola, J. A. (1923). Patente de Invención 85998. Madrid, 30 de junio de 1923. Archivo Histórico de la Oficina Española de Patentes y Marcas (OEPM).

Ariza Carbonell, J. (1875). Privilegio de Introducción 5370. Madrid, 2 de noviembre de 1975. Archivo Histórico OEPM.

Barberá Humbert, J. y Maña Solé, D. (1904). Patente de Invención 34022. Barcelona, 18 de mayo de 1904. Archivo Histórico OEPM.

Bori R. y Gardó J. (1928). Manual Práctico de Publicidad. Volumen I y II. Barcelona: Editorial Cultura.

Bori R. y Gardó J. (1931). Tratado completo de publicidad y propaganda. Barcelona: José Montesó Editor.

Bori R. y Gardó J. (1936). Tratado completo de publicidad y propaganda. Barcelona: José Montesó Editor.

District. (1876). District Intelligence, Cardiff. Country Court. South Walles Daily News, Saturday October $28,1876,6$.

Echegaray, J. (1895). Crónica científica. Dos inventos novísimos. El Liberal, 5711. Madrid, jueves 23 de mayo de 1895, 1.

Eguizábal, R. (1998). Historia de la publicidad. Madrid: Eresma y Celeste Ediciones.

Ewen, S. (1976). Captains of consciousness: Advertising and the social roots of the consumer culture New York: M Graw Hill.

Fernández Alfageme, A. (1905). Patente de Invención 36742. Barcelona, 2 de septiembre de 1905. Archivo Histórico OEPM.

Frutos Esteban, F. J. y López San Segundo, C. (2010). La vuelta al mundo de la linterna mágica en ochenta vistas. Fonseca. Journal of Communication, 1, 1-32.

Frutos Esteban, F. J. (2008). La linterna mágica: de la invención a la decadencia (siglos XVIII-XX). Historia Contemporánea 36, 9-32.

Herbert, S. (1997). Lanterns for Advertising. En D. Crompton, R. Franklin y S. Herbert (eds.), Servants of Light: the book of the lantern (pp. 80-85). London: Magic Lantern Society.

Hetch, H. (1993). Pre-Cinema History. An Encyclopaedia and Annotated Bibliography of the Moving Image Before 1896. London: British Film Institute.

\footnotetext{
$2<$ https://www.slides.uni-trier.de/index.php $>$.

$3<$ http://linternauta.docenciavirtual.es/>.

$4<$ https://www.luikerwaal.com/index.htm $>$.
} 
Humphries, S. (1989). The Hard Sell. En S. Humphries, Victorian Britain Through the Magic Lantern (pp. 121-131). London: Sidwick \& Jackson.

Jordana y Morera, J. (1876). Crónicas de Filadelfia. Revista de España, 50. Madrid, mayo-junio de 1876, 212-223.

Lefebvre-Duruflé. (1868). Brevet 80372. Paris, 7 avril 1868. Bulletin des lois de la République Française, XII Série de 1872. Paris: Imprimerie Nationale, 1873, p. 238.

Leroux, G. (1925). La Mansarde en Or. Le Journal. Paris, 11 decembre 1925, 2.

Ligue (1889). Ligue des patriotes. La lanterne: journal politique quotidiene, 4333. Paris, Samedi, 2 mars $1889,1$.

Llanos, L. (1888). Carta de Bruselas. La Vanguardia, 452. Barcelona, lunes 24 de septiembre de 1888, 1.

Marchand, R. (1985). Advertising the American Dream. Making way for modernity. 1920-1940. Los Angeles: University of California Press.

Marín, R. (1901). Patente de invención 28476. Madrid, 09 de septiembre de 1901. Archivo Histórico de la OEPM.

Márquez y Anglada, F. (1892). Patente de Invención 13535. Madrid, 12 de julio de 1892. Archivo Histórico OEPM.

Müller-Kolb, D. (2015). Advertising with Light. Commerce and the Magic Lantern. The magic lantern: number 2, 6-8.

Murga Machado, L. (1897). Patente de Invención 20915. Sevilla, 26 de mayo de 1897. Archivo Histórico OEPM.

Nouvelles. (1887). Nouvelles et Echos. Aujourd'hui. Gil Blas, 2763. Paris, Mercredi 13 avril 1887, 1.

Obstruction. (1899). Obstruction Case. The weekly Standard and Express. Saturday, March 25, 1899, 6.

Olaeta. (1894). Nuevo modo de anunciar. El correo Español: diario tradicionalista, 1615. Madrid, sábado 27 de enero de 1894, 1-2.

Puig, J. J. (1986). La publicidad: historia y técnicas. Barcelona: Ediciones Mitre.

Robinson, D. Herbert, S. y Crangle R. (2001). Enciclopaedia of the Magic Lantern. London: Magic Lantern Society.

Sánchez Galán, M. B. (2010). La publicidad y la imagen en movimiento. Primeros pasos del cine publicitario en España. Pensar la Publicidad, 4-1, 79-96.

Sánchez Galán, M. B. (2003). Usos publicitarios de la linterna mágica. En A. Quintana, Imatge i viatge. De les vistes òptiques al cinema: la configuración de l'imaginari turistic (pp. 175-180). Girona: Fundació Museu del Cinema-Col.lecció Tomàs Mallol, Ayuntament de Girona y Universitat de Girona.

Shudson, M. (1993). Advertising, the uneasy persuasion. London: Routledge.

Simón Palmer, M. C. (1977). La publicidad en las calles madrileñas durante el siglo XIX. Anales del Instituto de Estudios Madrileños. Tomo XIV. Madrid: CSIC.

Toll, J. (1899). Patente de Invención 25129. Barcelona, 30 de noviembre de 1899. Archivo Histórico OEPM.

Unsaín, J. M. (1985). El cine y los vascos. San Sebastián: Editorial Eusko-Ikaskuntza. Sociedad de Estudios Vascos.

Valldecabres Pechuán, O. (1893). Patente de Invención 14944. Valencia, 13 de septiembre de 1893. Archivo Histórico OEPM.

Zunzunegui, S. (1995). El cine en el País V asco. Diputación Foral de Vizcaya.

Wright, A. C. (1895). Patente de Invención 17119. Madrid, 9 de marzo de 1895. Archivo Histórico OEPM.

Writing. (1892). Writing on the clouds. The New York Times, New York, December 25, 1892. 